\title{
EFEKTIVITAS PENERAPAN SISTEM DAN PROSEDUR AKUNTANSI AKTIVA TETAP BERDASARKAN PSAK 16 TAHUN 2011 DALAM EKONOMI SYARIAH
}

\author{
Risna Nurhaida Hafni ${ }^{1}$, Ruhadi ${ }^{2}$, Rizky Maidan Ilmi $^{3}$ \\ 1. Program Pascasarjana Ekonomi Syariah UIN Sunan Gunung Djati Bandung, \\ nurhaidarisna@gmail.com \\ ${ }^{2.3}$ Program Pascasarjana Ekonomi Syariah UIN Sunan Gunung Djati Bandung
}

\begin{abstract}
Today, the development of industry 4.0 is pushing for faster and faster development growth. Therefore, the role played in managing fixed assets in a company is very important in order to support the safety of the company in planning, procuring, and maintaining assets properly. Therefore, decision makers in maintaining fixed assets require expertise and policies specifically regarding financial accounting. The research method used in this research is a qualitative descriptive method, data collection is done by combining theories from various sources. In this study aims to determine the use of fixed assets based on PSAK 16 of 2011 in Islamic Economics. The results of this study are expected to be an additional value in the science reference related to Islamic economics. The findings in this study that the use of fixed assets that refer to PSAK 16 of 2011 is a revision of PSAK 16 of 2007, where the use of sharia accounting regarding fixed assets that are used still in conventional accounting. This is expected to have an adequate Islamic economic instrument as a sign that it is important to build a strong economic system based on the Koran and the Sunnah.
\end{abstract}

Keywords: Fixed Assets, PSAK 16, Islamic Economics

\begin{abstract}
ABSTRAK
Dewasa ini, perkembangan industri 4.0 mendorong pada pertumbuhan pembangunan yang semakin cepat dan pesat. Maka dari itu, peran yang dimainkan dalam pengelolaan aset tetap pada sebuah perusahaan sangatlah penting demi menunjang keselamatan perusahaan dalam perencanaan, pengadaan, serta pemeliharaan aset dengan baik. Maka dari itu, para pengambil keputusan dalam memelihara aktiva tetap diperlukan keahlian serta kebijakan secara khusus mengenai ilmu akuntansi keuangan. Metode penelitian yang digunakan dalam penelitian ini adalah metode deskriptif kualitatif, pengumpulan data dilakukan dengan menggabungkan teori dari berbagai sumber. Dalam penelitian ini bertujuan untuk mengetahui penggunaan aktiva tetap berdasarkan PSAK 16 Tahun 2011 dalam Ekonomi Islam. Hasil penelitian ini diharapkan akan menjadi nilai tambahan dalam referansi ilmu yang berhubungan dengan ekonomi Islam. Temuan dalam penelitian ini bahwa penggunaan aktiva tetap yang merujuk pada PSAK 16 Tahun 2011 merupakan revisi dari PSAK 16 Tahun 2007, dimana penggunaan akuntansi
\end{abstract}


syariah mengenai aktiva tetap yang digunakan masih menginduk pada akuntansi konvensional. Hal ini diharapkan adanya perangkat ekonomi Islam yang memadai sebagai tanda bahwa betapa pentingnya membangun system perekonomian yang kuat berlandaskan Al-Quran dan Sunnah.

\section{Kata Kunci: Aktiva Tetap, PSAK 16, Ekonomi Syaraiah}

\section{PENDAHULUAN}

Ekonomi Islam dilahirkan untuk menjelaskan bagaimana pandangan Islam mengenai kehidupan. Karena ekonomi Islam inilah merupakan salah satu pilar yang dapat menyambungkan antara dunia akhirat, serta individu dan masyarakat. Dalam individu diseimbangkan antara jasmani dan rohani, akal dan hati, serta realita dan fakta (Sabrina, 2013), yang salah satunya dibuktikan dengan adanya perkembangan industri 4.0 pada saat ini terjadi sangat cepat dan pesat. Dari perkembangan itulah melahirkan kemajuan dalam berbagai bidang, seperti: bidang ekonomi, bidang ilmu pengetahuan, serta tak kalah canggihnya dalam bidang teknologi.

Begitupun dengan perkembangan pada perusahaan yang dimana perkembangan industri 4.0 ini harus didukung secara penuh dengan hadirnya perlengkapan serta peralatan yang memadai dalam mengelola aktiva tetap.

Penggunaan Aktiva tetap merupakan salah satu alat yang dapat memberikan informasi terhadap laporan necara yang menggambarkan kekayaan serta potensi ekonomi yang dimiliki. Sehingga, dari laporan akuntansi tersebut masyarakat dapat menilai berbagai hal, seperti: dilakukan untuk menarik perhatian para investor, potensi keuntungan yang diperoleh, memberikan pelayanan dengan melengkapi sarana dan prasarana kepada public, ataupun hal yang lainnya.

Pengelolaan aktiva tetap pada suatu perusahaan baik dalam bidang jasa, perusahaan dagang, atau perusahaan manufaktur diperlukan keahlian secara khusus. Hal ini tiada lain dari tujuan sebuah perusahaan yaitu mencari keuntungan. Perusahaan merupakan mencangkup pertumbuhan yang berlangsung lama, kelangsungan hidup, serta memberikan sesuatu hal yang positif bagi masyarakat (Rusdianto, 2017).

Dalam rangka mendukung segala operasional dalam perusahaan, tidak menutup kemungkinan perusahaan akan memaksimalkan pemanfaatan aset yang dimiliki. Untuk itu, aset memiliki berbagai jenis yang dapat diklasifikasikan berdasarkan sifat aktivitas usaha yang dijalankan oleh suatu perusahaan. Salah satu subklasifikasi dari aset adalah aset tetap, merupakan bagian terpenting dalam suatu perusahaan baik ditinjau dari segi fungsinya, jumlah dana yang diinvestasikan maupun pengawasannya (Sari, 2018).

Selain itu, sebagaimana yang dijelaskan diatas bahwa kekayaan dapat menggambarkan kondisi suatu perusahaan. Maka, diharuskan untuk melakukan pengelolaan aset yang baik. Hal ini akan diuntungkan sebagai modal awal bagi perusahaan itu sendiri dalam melakukan pengembangan kemampuan keuangannya. 
Begitupun sebaliknya, apabila suatu aset tersebut tidak dilakukan dengan baik, maka akan menimbulkan beban biaya yang harus dikeluarkan, seperti biaya perawatan atau pemeliharaan yang seiring dengan berjalannya waktu nilai dari suatu aset tersebut menurun (depresiasi).

Dalam pengelolaan aset tetap tersebut, diperlukan landasan agar terhindar dari kesalahan yang cukup material, karena hal ini berdampak pada nilai investasi yang ditanamkan untuk aset pada umumnya relative besar. Maka dari itu, tujuan dari diberlakukannya aktiva tetap dalam akuntansi adalah laporan keuangan yang diperuntukkan pengguna bisa memberikan informasi mengenai investasi entitas pada aset tetap, dan perubahan dalam investasi tersebut. Isu utama yang tejadi pada aset tetap adalah pengakuan aset, penentuan jumlah yang tercatat, pembebanan penyusutan, serta rugi penurunan nilai atas aset tetap.

\section{LITERATUR REVIEW}

Islam sebagai agama rahmatan lil 'alamin. Secara komprehensif dalam Islam menekankan adanya pembebasan dari belenggu keterpasungan hidup yang diakibatkan oleh ketidakberdayaan dalam mengelola segala sumber daya (Rafiqi, 2016).

Pada dasarnya, harta yang dijadikan sebagai subklasifikasi sumber daya yang dimiliki oleh segenap umat manusia bisa dilakukan dengan apasaja termasuk didalamnya dapat menjadikan sebagai kekuatan untuk menegakkan kebenaran (Hafidhuddin, 2007). Dampak dari ketidakberdayaan itulah menjadikan sebagai celah adanya problematika sosial, seperti kemiskinan yang merajalela serta keterbatasan akses untuk memperoleh kehidupan yang layak atau sejahtera.

Umar Ibnul Khattab dalam kepemimpinannya mengatakan bahwa: "Saya tidak ingin menjadi keledai mati karena kelaparan pada saat saya menjadi khalifah.” (Hafidhuddin, 2007). Dalam ucapan umar tersebut dapat diartikan bahwa umat manusia pada khusunya kaum muslimin yang taat harus menjadikan harta sebagai penyelamat, tidak hanya untuk manusia, melainkan hewan lemah seperti keledai.

Oleh karena itu, dalam memanfaatkan harta agar bisa bertambah dan berkah Allah swt memberikan keleluasaan untuk berjual beli atau melakukan transaksi dengan syarat tidak melakukan sesuatu hal yang telah disyariatkan oleh-Nya. Menurut Didin Hafidhuddin, hal-hal yang harus diperhatikan dalam cara perolehan harta, diantaranya: (Hafidhuddin, 2007)

1. Halal (substansi maupun caranya),

2. Tidak berlaku dzalim,

3. Tidak dengan cara-cara yang bathil. Seperti:

a. Suap menyuap (risywah)

b. Menipu dan korupsi

c. Berbuat riba

d. Mempermainkan takaran, timbangan dan kualitas

e. Memfitnah dan cara-cara yang tidak benar lainnya. 
Untuk itu, dalam melakukan transaksi diperlukan pencatatan yang akurat sehingga dapat dipertanggungjawabkan, atau lebih dikenal dengan istilah akuntansi, merupakan salah satu komponen yang memiliki peran yang sangat penting dalam menjalankan segala aktivitas pada perusahaan (Riahi, 2011). Akuntansi menurut Hongren dan Harrison (Harahap S, 2007) adalah sistem informasi yang mengukur aktivitas bisnis, memproses data menjadi laporan, dan mengkomunikasikan hasilnya kepada para pengambil keputusan.

Berdasarkan pengertian tersebut dapat disimpulkan bahwa akuntansi adalah suatu sistem informasi yang meliputi proses mengidentifikasikan, mengukur, dan melaporkan informasi ekonomi dan mengkomunikasikan hasilnya dalam bentuk laporan keuangan diinformasikan kepada pengguna laporan keuangan untuk dijadikan sebagai pertimbangan pengambilan keputusan.

Begitupun kelebihan yang diberikan pada akuntansi merupakan sebagai pengelolaan informasi keuangan yang tidak hanya mencatat pada pembuatan produk baru yang nantinya dijual ke masyarakat, melainkan dalam akuntansi juga terdapat pengelolaan keuangan yang terdapat pada aset tetap.

American institute of Certified Public Accounting (AICPA) menjelaskan mengenai akuntansi, adalah seni pencatatan, penggolongan dan pengikhtisaran dengan cara tertentu dan dalam ukuran moneter, transakasi dan kejadian-kejadian yang umumnya bersifat keuangan dan termasuk menafsirkan hasil-hasilnya (Harahap S, 2007).

Dalam penulisan laporan keuangan, akuntansi konvensional lebih dikenal dan dikembangkan dengan alasan mudah difahami berdasarkan tata nilai yang ada dalam masyarakat barat, maka kerangka konseptual yang dipakai sebagai dasar pembuatan dan pengambangan standar akuntansi berpihak kepada kelompok kepentingan tertentu.

\section{METODE}

Metode penelitian yang digunakan dalam penelitian ini merupakan metode deskriptif kualitatif. Dimana pengumpulan data dilakukan dengan cara mencari sumber terkait yang berhubungan dengan masalah yang akan dibahas oleh penulis, kemudian menggabungkan teoriteori yang ditemukan dari berbagai sumber tersebut (Sugiono, 2013).

\section{HASIL DAN PEMBAHASAN}

\section{HASIL}

Runtuhnya perusahaan besar seperti Enron, Worldcom dan Global Crossing di Amerika Serikat dan Parmalat di Italia telah jelas menggulingkan kredibilitas dan akuntabilitas laporan keuangan. Skandal-skandal tersebut terjadi bukan karena akuntansinya, melainkan akuntan dan pelaku bisnis yang tidak beretika (FORDEBY, 2017).

Mevliyar Er (Er, 2008) mengemukakan bahwa dalam sebuah studi bahwa negara-negara Muslim memiliki skor yang lebih buruk dari pada negara-negara non Muslim. Transparancy International Indeks persepsi korupsi walaupun setingginya persentasi orang yang percaya pada 
Tuhan mungkin sebagian kemiskinan yang relative lebih tinggi dari pada yang terjadi di dunia industri. Hal ini menunjukkan bahwa krisis etika telah tersebar diseluruh belahan penjuru dunia.

Untuk itu, dalam akuntansi tidak hanya cukup bila sekedar pembelajaran saja. Akan tetapi diharuskan adanya penanaman nilai-nilai etika (FORDEBY, 2017), yang bertujuan untuk menjamin bahwa para akuntan professional bertindak secara etis sesuai dengan kapasitas mereka.

\section{PEMBAHASAN}

Reeve, mengemukakan bahwa yang dimaksud dengan aset tetap adalah aset yang memiliki sifat jangka panjang atau relative memiliki sifat permanen serta dapat digunakan dalam jangka panjang (Revee.J.M, Warren.C.S, Duchac.J.E, Wahyuni.E.T, Soepriyanto.G, Jusuf.A.A, 2010). Menurut Libby yang dimaksud dengan aset tetap adalah sumber daya berwujud yang dimiliki perusahaan dan digunakan dalam operasi selama beberapa tahun (Libby.R, Libby.P.A, 2008).

Sedangkan berdasarkan PSAK No.16 Revisi 2011 (Indonesia, 2011) Aset tetap adalah aset berwujud yang: 1) dimiliki untuk digunakan dalam produksi atau penyediaan barang atau jasa untuk direntalkan kepada pihak lain atau untuk tujuan administrative, dan 2) diharapkan untuk digunakan selama lebih dari satu periode.

PSAK 16 tahun 2011 merupakan pembaharuan dari PSAK 16 tahun 2007, maka dari itu pembaharuan secara ringkas pada PSAK 16 tersebut adalah sebagai berikut: (Indonesia, 2011)

\begin{tabular}{|c|c|c|c|}
\hline No & Perihal & PSAK 162011 & PSAK 162007 \\
\hline & $\begin{array}{l}\text { Pengecualian } \\
\text { terjadap ruang } \\
\text { lingkup }\end{array}$ & $\begin{array}{l}\text { Menambahkan } \\
\text { pengecualian rung lingkup } \\
\text { untuk: } \\
\text { Aset tetap } \\
\text { diklasifikasikan sebagai } \\
\text { dimiliki untuk dijual sesuai } \\
\text { dengan PSAK } 58 \text { Tahun 2009: } \\
\text { Aset tidak lancar yang dimiliki } \\
\text { untuk dijual dan operasi yang } \\
\text { dihentikan. } \\
\text { Pengakuan } \\
\text { pengukuran aset eksplorasi dan } \\
\text { evaluasi. Pada PSAK 64: } \\
\text { Aktivitas eksplorasi dan } \\
\text { evaluasi pada pertambangan } \\
\text { sumber daya mineral. }\end{array}$ & $\begin{array}{l}\text { Hanya } \\
\text { mengatur pengecualian } \\
\text { ruang lingkup untuk } \\
\text { hak pembangunan dan } \\
\text { reservasi tambang, } \\
\text { seperti; minyak, gas } \\
\text { alam, dan sumber daya } \\
\text { alam sejenis yang tidak } \\
\text { dapat diperbaharui. }\end{array}$ \\
\hline & Ruang lingkup & $\begin{array}{l}\text { Tidak mengatur lagi } \\
\text { mengenai property investasi } \\
\text { yang sedang dibangun atau } \\
\text { dikembangkan. }\end{array}$ & $\begin{array}{l}\text { Ruang lingkup } \\
\text { mencangkup property } \\
\text { yang dibangun atau } \\
\text { dikembangkan untuk } \\
\text { digunakan dimasa }\end{array}$ \\
\hline
\end{tabular}




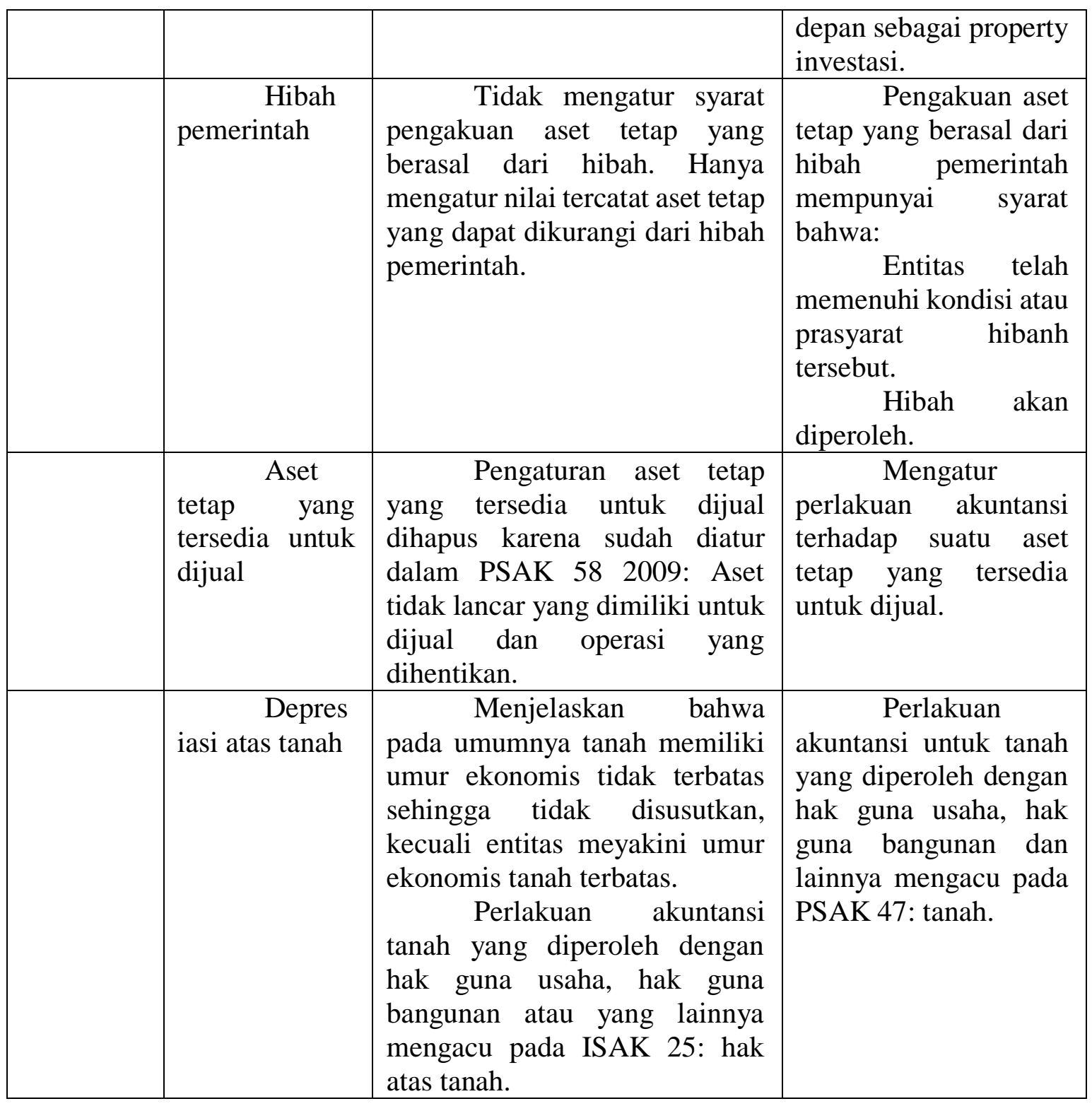

Berdasarkan hasil revisi antara PSAK 16 tahun 20011 dengan PSAK 16 tahun 2007 menjelaskan bahwa keuntungan dari penggunaan sistem akuntansi ini menjadikan salah satu upaya untuk dapat menjaga asset yang dikelola terjaga accountability-nya sehingga tidak ada yang dirugikan dari berbagai pihak. Upaya untuk mencapai keadilan baik dalam pelaksanaan transaksi utang-piutang maupun dalam hubungan kerja sama antara berbagai pihak seperti dalam persekutuan, musyarakah, dan mudharabah, semuanya memerlukan sarana pencatatan yang tidak merugikan satu sama lainya sebagaimanya.

Dalam kaidah fikih disebutkan untuk mencapai sesuatu yang diwajibkan maka sarana untuk mencapainya pun menjadi wajib. Oleh karena itu, dapat disebutkan bahwa memelihara pencatatan baik sebagai informasi, untuk menyasikan, untuk pertanggungjawaban, untuk pemeliharaan hak, atau untuk keadilan maka hukumnya termasuk menjadi wajib. 


\section{KESIMPULAN}

Makna kepemilikan dalam Islam, pada hakikatnya adalah atas kepemilikan Allah swt, manusia hanyalah diberikan amanat dalam pengelolaan atau menjaga dengan baik dari apa yang Allah swt berikan. Begitupun dalam akuntansi, berdasarkan Al-quran dan Hadis yang memiliki sifat umum dan menyeluruh, meliputi seluruh aktivitas manusia dalam kehidupan berinteraksi dan bertransaksinya dalam hubungannya dengan ibadah maupun transaksi sosial ekonomi. Hanya saja, ilmu akuntansi pada saat ini lebih mengedepankan ilmu akuntansi konvensional, sehingga ilmu akuntansi berdasarkan syariat masih dikesampingkan dan menginduk terhadap akuntansi konvensional. Untuk itu, diharapkan adanya perangkat ekonomi Islam yang memadai sebagai tanda bahwa betapa pentingnya membangun system perekonomian yang kuat serta kaffah, berlandaskan Al-Quran dan Sunnah.

\section{REFERENSI}

Er, M. (2008). Corruption from the Islamic perspective : Some recommendations for the MENA Region. International Journal of Islamic and Middle Eastern Finance and Management, $1(1), 31-51$.

FORDEBY, Ade. (2017). Akuntansi Syariah Seri Konsep dan Aplikasi Ekonomi dan Bisnis Islam (1st ed.). Jakarta: Rajawali Pers.

Hafidhuddin, D. (2007). Agar Harta Berkah dan Bertambah (1st ed.). Jakarta: Gema Insani Press.

Harahap S, S. (2007). A Statement of Basic Accounting Theory (ASOBAT). Jakarta: Raja Grafindo Persada.

Indonesia, I. A. (2011). Pernyataan Standar Akuntansi Keuangan Aset Tetap ED PSAK 16 (revisi 2011). Jakarta: Dewan Standar Akuntansi Keuangan.

Libby.R, Libby.P.A, S. D. G. (2008). Akuntansi Keuangan. Edisi kelima. Yogyakarta: Andi.

Rafiqi, Y. (2016). IMPLIKASI AMANDEMEN UNDANG-UNDANG TENTANG ZAKAT TERHADAP OPTIMALISASI PENGUMPULAN DAN PEMBERDAYAAN ZAKAT. Ekonomi Syariah, 1(1), 33-46.

Revee.J.M, Warren.C.S, Duchac.J.E, Wahyuni.E.T, Soepriyanto.G, Jusuf.A.A, D. C. D. (2010). Pengantar Akuntansi adaptasi Indonesia Jilid 2. Jakarta: Salemba Empat.

Riahi, A. \& B. (2011). Accounting Theory: Buku satu. Edisi 5. Jakarta: Salemba Empat.

Rusdianto, N. I. R. (2017). PERLAKUAN AKUNTANSI ASET TETAP BERDASARKAN PSAK NO. 16 PADA PT. SWADAYA GRAHA DI GRESIK. Gema Ekonomi Fakultas Ekonomi, 06(16), 42-50. 
Sabrina, I. (2013). KONTRIBUSI ISLAM TERHADAP AKUNTANSI. Al-Iqtishad, V(1), 289-304.

Sari, D. I. (2018). Analisis Depresiasi Aktiva Tetap Metode Garis Lurus dan Jumlah Angka Tahun PT Adira Dinamika. Moneter, V(1), 86-92.

Sugiono. 2013. Metode Penelitian Bisnis, Bandung, Alfabeta. 